\title{
Humor and Trauma-Related Psychopathology Among Survivors of Terror Attacks and Their Spouses
}

\author{
Avi Besser, Michael Weinberg, Virgil Zeigler-Hill, Yochai Ataria, and Yuval Neria
}

\begin{abstract}
The goal of this study was to examine the bidirectional relationships between humor and trauma-related psychopathology (posttraumatic stress disorder [PTSD], depression, and anxiety symptoms) among 105 dyads consisting of Israelis who were injured during terror attacks and their spouses $(N=210)$. An actor-partner interdependence model (APIM) was applied as part of a structural equation modeling (SEM) analysis aimed at examining the associations between the use of different styles of humor and trauma-related psychopathology. Consistent with our hypotheses, results suggested that benign styles of humor were associated with survivors' lower levels of trauma-related symptoms (actor effects) and also had a buffering effect for the spouse (partner effects). More specifically, the use of self-enhancing humor by survivors was negatively associated with spousal symptoms and the use of affiliative humor by spouses was negatively associated with psychopathology symptoms reported by survivors. The results of this study shed light on the role that benign humor may play in coping with traumatic events while taking into account the dyadic relationships among survivors and their spouses. Theoretical and clinical implications of the findings are discussed.
\end{abstract}

The role of traumatic exposure in the development and maintenance of traumarelated psychopathology has attracted considerable attention across societies and geographic regions (e.g., Neria, Nandi, \& Galea, 2008). In this context, the global proliferation of terror attacks in recent decades has focused the world's attention on the psychological effects of terrorism (Neria, DiGrande, \& Adams, 2011; Shalev \& Freedman, 2005). Numerous studies have examined the mental health consequences of exposure to these events, mainly for the direct survivors, examining their posttraumatic stress disorder (PTSD), depression, and anxiety symptoms as well as resilience

Avi Besser, $\mathrm{PhD}$, is affiliated with the Department of Behavioral Sciences and Center for Research in Personality, Life Transitions, and Stressful Life Events at Sapir Academic College in Sderot, Israel. Michael Weinberg, PhD, is affiliated with the School of Social Work, Faculty of Social Welfare and Health Sciences, at the University of Haifa in Haifa, Israel, and the research department of the OneFamily organization in Jerusalem, Israel. Virgil Zeigler-Hill, $P h D$, is affiliated with the Department of Psychology at Oakland University in Rochester, Michigan. Yochai Ataria, $\mathrm{PhD}$ candidate, is affiliated with the Hebrew University of Jerusalem, Jerusalem, Israel, and the Department of Neurobiology at the Weizmann Institute of Science in Rehovot, Israel. Yuval Neria, PhD, is affiliated with the New York State Psychiatric Institute and the Departments of Psychiatry and Epidemiology at Columbia University Medical Center in New York City.

Address correspondence to Avi Besser, Center for Research in Personality, Life Transitions, and Stressful Life Events, Sapir Academic College, D. N. Hof Ashkelon, 79165, Israel. E-mail: besser@mail.sapir.ac.il 
in exposed individuals (e.g., Brookmeyer, Henrich, Cohen, \& Shahar, 2011; Henrich \& Shahar, 2008; Shahar, Cohen, Grogen, Barile, \& Henrich, 2009; Soffer-Dudek, Vertheim, \& Shahar, 2011; for a review, see Weinberg, Besser, Campeas, Shvil, \& Neria, 2012).

Clinical observations and empirical studies have indicated that the consequences of traumatic events are not limited to the survivors because they often have an important impact on significant others in the survivors' environment (Dekel, Goldblatt, Keidar, Solomon, \& Polliack, 2005). In particular, the efforts of significant others to support traumatized survivors may lead them to experience distress. Previous literature has described how significant others often adopt the traumatized partners' feelings, experiences, and memories as their own (Figley, 1995). This may sometimes lead significant others to exhibit secondary traumatic stress symptoms (Catherall, 1992; Figley, 1995). Spouses-who are often the survivors' main caregivers-are particularly vulnerable to secondary trauma stemming from these experiences (Galovski \& Lyons, 2004; Weinberg, 2011, 2013).

Recent research has suggested that the survivor-spouse relationship is bidirectional (Nelson-Goff \& Smith, 2005). That is, the survivor of the traumatic experience affects the unexposed spouse and is affected by the unexposed spouse. Previous research has demonstrated the bidirectional relationship between trauma survivors and their spouses in terms of coping mechanisms, attachment styles, and PTSD symptoms (Ein-Dor, Doron, Solomon, Mikulincer, \& Shaver, 2010; Gilbar, Weinberg, \& Gil, 2012; Henry et al., 2011; Weinberg, 2013). However, the mechanisms by which personality dimensions confer vulnerability or resilience for survivors and their spouses have scarcely been examined. We believe that humor-particularly individual differences in the use of benign rather than injurious styles of humor-may play an important role in this context that has largely been neglected. Previous studies have demonstrated the importance of humor as an affect-regulation strategy, particularly within interpersonal relationships (e.g., Besser, Luyten, \& Blatt, 2011; Besser, Luyten, \& Mayes, 2012; Besser \& Zeigler-Hill, 2011; Martin, 2007; Miczo, Averbeck, \& Mariani, 2009; Taber, Redden, \& Hurley, 2007; Zeigler-Hill \& Besser, 2011; Zeigler-Hill, Besser, $\&$ Jett, 2013). Congruent with these findings, humor has been shown to play an important role in resilience, serving as a vital internal resource when individuals are confronted with adversity (Fonagy, Steele, Steele, Higgitt, \& Target, 1994; Luyten, Fonagy, Lemma, \& Target, 2011; Martin, 2001, 2007; Vaillant, 2000). In light of this previous work, the present study examined the use of benign and injurious humor styles and their association with PTSD, depression, and anxiety symptoms among Israelis who were injured in terrorist attacks and their spouses.

Contemporary research on individual differences in humor has distinguished among four styles of humor (Martin, Puhlik-Doris, Larsen, Gray, \& Weir, 2003). Two of these styles are benign (i.e., affiliative and self-enhancing humor) and two are injurious (i.e., aggressive and self-defeating humor). Affiliative humor refers to benign humor that is used to enhance relationships by saying funny things or engaging in witty banter to amuse others; whereas selfenhancing humor is a benign humor that is used to enhance the self by activities such as maintaining a humorous perspective in the face of adversity, which may help with emotion regulation and coping. Aggressive humor refers to injurious humor that is used to enhance the self through sarcasm, teasing, or ridiculing others; whereas self-defeating humor is a form of injurious humor used to enhance relationships at a cost to the self through self-disparagement (Martin, 2007).

Although individuals that use selfdefeating humor may be considered funny, excessive use of this style of humor may lead others to dislike them. Similarly, the use of aggressive humor may be appropriate in some circumstances but is likely to lead to interpersonal conflicts when used indiscriminately 
(Kuiper \& Leite, 2010; Martin et al., 2003). A growing body of research has shown that benign and injurious styles of humor are differentially related to emotional and psychosocial stress, distress, and well-being, loneliness, relationship satisfaction, conflict, and being disliked by others. Benign humor is often associated with positive outcomes, whereas injurious humor is generally associated with negative outcomes (Besser \& Zeigler-Hill, 2011; Besser et al., 2011; Besser et al., 2012; Butzer \& Kuiper, 2008; Cann, Norman, Welbourne, \& Calhoun, 2008; Fitts, Sebby, \& Zlokovich, 2009; Kuiper \& Leite, 2010; Martin, 2007; Zeigler-Hill \& Besser, 2011; Zeigler-Hill et al., 2013).

Research suggests that humor styles may play an important role in stress regulation and resilience (Fonagy et al., 1994; Luyten et al., 2011; Martin, 2001, 2007; Vaillant, 2000). Besides its intrapsychic functions, humor also serves important interpersonal functions (Martin, 2007). Yet while the use of appropriate humor may foster communication and strengthen relationships, which may decrease levels of distress in both the individual expressing the humor and his or her audience (Gervais \& Wilson, 2005; Martin, 2007; Taber et al., 2007), the use of inappropriate humor may lead to conflict and tension in interpersonal relationships, particularly close interpersonal relations (Cann et al., 2008). In the realm of trauma research, affiliative humor has been found to be associated with resilience and fewer PTSD symptoms, but injurious humor styles have not been found to be associated with negative outcomes (Agaibi \& Wilson, 2005; Henman, 2001). Nevertheless, humor has been found to be associated with the emotional distress of survivors, whereas no attention has been given to its role in the distress of their unexposed spouses. Moreover, despite growing knowledge regarding the bidirectional survivor-spouse relationship, to date no studies have examined the associations between the humor styles of both the survivors and their spouses and the PTSD, depression, and anxiety symptoms that they report. The present study was an attempt to bridge this existing gap in the empirical literature.

The present study examined the following hypotheses. First, we expected to find significant positive associations between the PTSD, depression, and anxiety symptoms of trauma survivors and their spouses. Second, we expected to find negative associations between the use of benign humor styles and levels of PTSD, depression, and anxiety symptoms. Third, we expected that bidirectional relationships would emerge for trauma survivors and their spouses such that the use of benign humor by one member of the dyad would be associated with the PTSD, depressive, and anxiety symptoms of the other member of the dyad. We did not have clear predictions for the injurious humor styles, but we included these forms of humor in the present study for exploratory purposes and reportorial completeness.

\section{METHOD}

\section{Participants}

This study focused on Israeli couples in which one member of the dyad had survived a terrorist attack. The eligible participants were drawn from the records of the OneFamily organization, which is an Israelbased foundation that provides assistance to survivors of terrorism regardless of religion, nationality, gender, or financial situation. To be eligible for the present study, participants had to meet each of the following criteria: (a) one member of the couple must have survived a terrorist attack no earlier than 2001, (b) the survivor must be recognized as being at least $20 \%$ disabled by the National Insurance Institute (Israel), (c) the survivor must be married, (d) the survivor must currently be between the ages of 21 and 70, and (e) the survivor must have been at least 18 years of age at the time of the attack. We located 182 couples who met our inclusion criteria. Of these 182 couples, 
23 couples could not be reached due to outdated contact information, 48 couples declined to participate, and six couples failed to complete all of the necessary questionnaires. Thus, the final sample consisted of 105 married couples $(N=210)$. The data for the present study were taken from a larger project designed to study the mental health consequences of terrorist attacks for the survivors and their spouses.

Of the 105 survivors who participated, 65 were men and 40 were women. The mean age of the survivors was 49.32 years $(S D=11.05)$, and the mean age of their spouses was 48.47 years $(S D=11.20)$. The mean number of years of education for the survivors was 12.72 years $(S D=2.83)$, and the mean number of years of education for the spouses was 12.70 years $(S D=2.50)$. The mean number of years of marriage for the 105 couples was 24.33 years $(S D=11.17)$. All of the couples had been involved in an intimate relationship with each other for at least three years prior to the terrorist attack. No statistical differences in demographic features were found between couples who consented to participate in the study and those who did not.

The terror attacks experienced by the survivors fell into three broad categories: 42 survivors had been exposed to a suicide bomber or explosive attack; 40 survivors had been exposed to rockets or a mortar attack; and 23 survivors had been exposed to a shooting, stabbing, or other direct physical assault. These attacks were significant events in the lives of these individuals, as indicated by the fact that 59 survivors (and 61 spouses) defined the survivors' injuries as severe and 78 survivors (and 69 spouses) noted that the attack had had a major negative impact on their lives. The mean number of years since the terror attack was 10.30 years $(S D=2.55)$.

\section{Procedure}

This study was approved by the Sapir Academic College Ethics Committee. All respondents provided written informed consent before participation after all procedures had been fully explained, and they were provided the opportunity to discontinue their participation at any time. None chose to do so. All interviews were conducted with efforts taken to ensure privacy and protect confidentiality. Following approval by the Sapir Academic College Ethics Committee, a letter was sent to the survivors and their spouses explaining the research project and requesting their consent to complete questionnaires. Representatives from the OneFamily organization, who were trained in the research procedures, helped the participants complete the questionnaires as needed. This assistance was limited to clarifying instructions, making sure all items were completed, and ascertaining that survivors and their spouses completed the questionnaires separately. Survivors and their spouses were asked to provide demographic information and information about the terror attack as well as complete instruments designed to capture their humor styles, PTSD symptoms, depressive symptoms, and anxiety symptoms.

\section{Measures}

\section{Humor Styles}

The Humor Styles Questionnaire (HSQ; Martin et al., 2003) was used to assess the use of benign and injurious humor styles. It is a 32-item measure that consists of four subscales that assess the use of the following styles of humor: affiliative (e.g., "I laugh and joke a lot with my friends"), self-enhancing (e.g., "My humorous outlook on life keeps me from getting overly upset or depressed about things"), aggressive (e.g., "If someone makes a mistake, I will often tease them about it"), and self-defeating (e.g., "I let people laugh at me or make fun at my expense more than I should"). Responses were made on scales ranging from 1 (Totally disagree) to 7 (Totally agree). Martin and colleagues (2003) demonstrated good reliability and validity for this measure. The internal consistency coefficients for the survivors' affiliative, selfenhancing, aggressive, and self-defeating 
subscales were $.84, .89, .70$, and.79, respectively. The general reliability of the HSQ scale (32 items) for the survivors was .90 . The internal consistency coefficient for the spouses' affiliative, self-enhancing, aggressive, and self-defeating subscales were $.67, .87, .64$, and .77 , respectively. The general reliability of the HSQ scale (32 items) for the spouses was .87.

\section{PTSD Symptoms}

PTSD symptoms were assessed using the PTSD Checklist-Civilian Version (PCL-C; Weathers \& Ford, 1996). This 17-item, selfadministered questionnaire is based on the diagnostic criteria for PTSD from the Diagnostic and Statistical Manual of Mental Disorders, Fourth Edition (DSM-IV; American Psychiatric Association, 1994). These criteria relate to three separate PTSD symptom clusters: reexperiencing (e.g., "Suddenly acting or feeling as if a stressful experience was happening again [as if you were reliving it]"), numbing/avoidance (e.g., "Avoiding activities or situations because they remind you of your stressful experience"), and hyperarousal (e.g., "Having difficulty concentrating"). Respondents were asked to rate the symptoms of PTSD they experienced during the past month (related to their exposure to the terror attack) using scales that ranged from 1 (Not at all) to 5 (Extremely). The total score on the PCL-C was the index of PTSD symptoms which ranged from 17 to 85 , with higher scores representing more severe PTSD symptoms. The internal consistency coefficients for the PCL-C were .94 for the survivors and .94 for the spouses.

\section{Depressive Symptoms}

The Patient Health Questionnaire-9 (PHQ-9; Kroenke, Spitzer, \& Williams, 2001) was used to examine depressive symptoms. The PHQ-9 scale is composed of nine items relating to symptoms of depression as defined by the DSM-IV. Each of the items is scored from 0
(Not at all) to 3 (Almost every day), resulting in a maximum total score of 27 , with higher scores representing more severe depression. The internal consistency coefficients for the PHQ-9 were .92 for the survivors and .90 for the spouses.

\section{Anxiety Symptoms}

The Generalized Anxiety Disorder Scale (GAD-7; Spitzer, Kroenke, Williams, $\&$ Lowe, 2006) was used to assess anxiety symptoms. The GAD is a seven-item instrument corresponding to the diagnostic criteria for generalized anxiety disorder. Participants were asked to respond to each item using scales that ranged from 0 (Not at all) to 3 (Almost every day). Scores for the GAD-7 ranged from 0 to 21 with higher scores representing higher levels of GAD symptoms. The internal consistency coefficients for the GAD-7 were .94 for the survivors and .93 for the spouses.

\section{Data Analyses}

The collected data were analyzed in three stages. First, SPSS 19 was used to examine the demographic statistics, frequency distributions, and descriptive statistics for the research variables. This allowed us to examine whether there were significant differences between the survivors and their spouses in terms of humor styles, PTSD symptoms, depressive symptoms, and/or anxiety symptoms. Second, bivariate analyses of the associations between the humor styles and symptoms (PTSD, depression, and anxiety) of survivors and their spouses were examined. Third, structural equation modeling (SEM; Hoyle \& Smith, 1994) was used to examine the bidirectional dyadic association of the humor styles and symptoms (a latent construct defined by three indicators: PTSD, depression, and anxiety) for the survivors and their spouses, using the actor-partner interdependence model (APIM; Kenny, Kashy, \& Cook, 2006). 
In APIM, the dyadic interaction is the unit of analysis (Kenny et al., 2006). In this type of model, each partner's independent variables are viewed as impacting the dependent variables of both partners. In the APIM framework, each dyad member is considered to be an actor as well as a partner in the dyad. These analyses control for the extent to which the unexposed spouse's symptoms are affected by the survivor's symptoms and vice versa. Therefore, the humor styles of the survivors (defined as measured variables) were defined to be associated with their symptoms (a latent variable that was defined by three manifest indicators: PTSD, depression, and anxiety). Similarly, the humor styles of the unexposed spouses were defined to be associated with their symptoms. These are referred to as actor effects. At the same time, the humor styles of the survivors were considered to be associated with the symptoms of their unexposed spouses, and the humor styles of the unexposed spouses were considered to be associated with the symptoms of the survivors. These are referred to as partner effects. The humor styles and symptoms of the survivors and their spouses were considered bidirectional associations (see Figure 1).

Analyses were conducted with AMOS (Version 18; Arbuckle, 2009) using the maximum-likelihood method. In addition to the overall $\chi^{2}$ test of exact fit, the following fit indices were used to evaluate the proposed models: (a) the $\chi^{2} / d f$ ratio, (b) the root mean square error of approximation (RMSEA), (c)

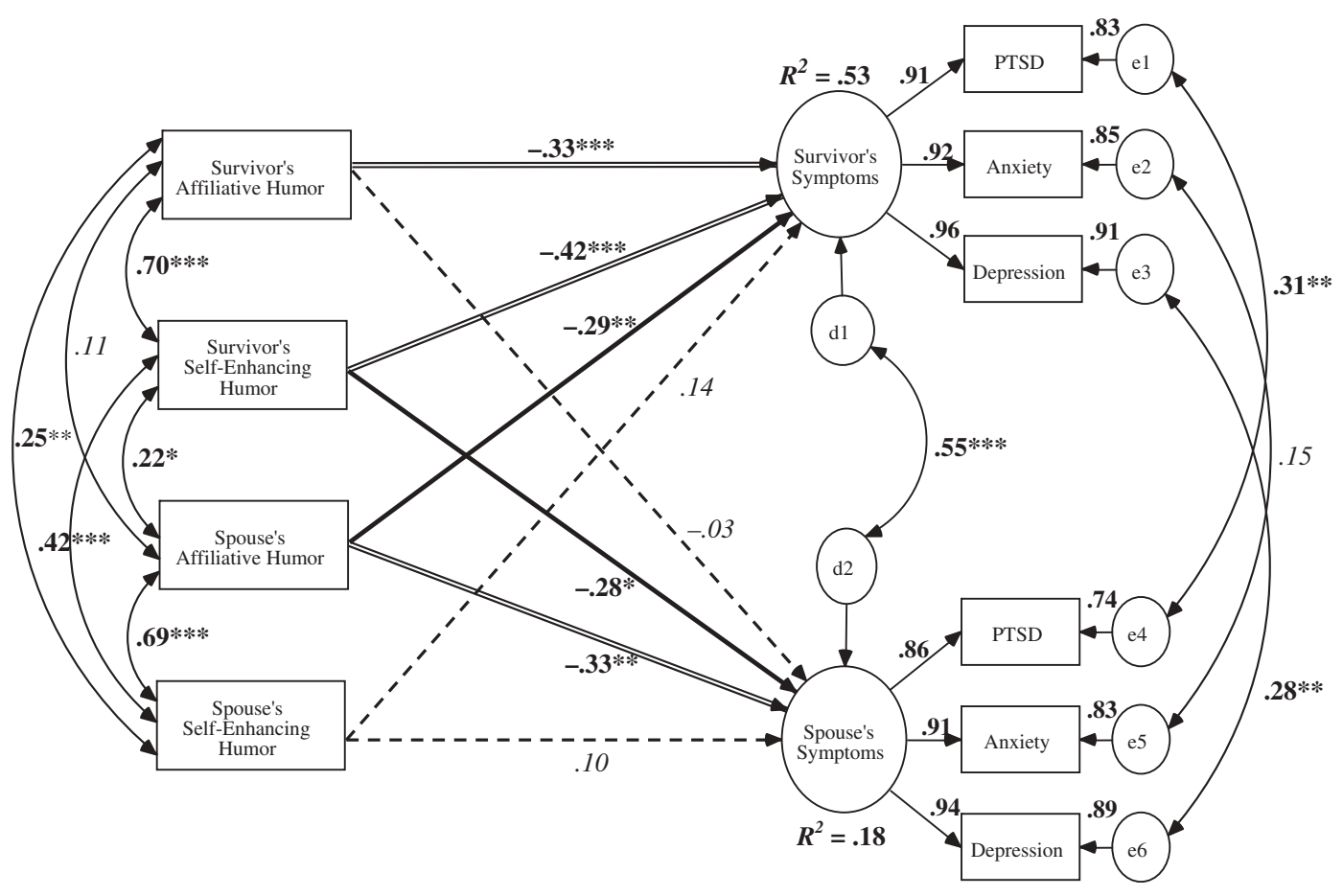

FIGURE 1. An actor-partner interdependence model of the effects of affiliative and self-enhancing humor on symptoms.Note. Rectangles indicate measured variables and large circles represent latent constructs. Small circles reflect residuals (e) or disturbances (d). Bold numbers above or near endogenous variables represent the amount of variance explained $\left(R^{2}\right)$. Bidirectional arrows depict covariance, and unidirectional arrows depict hypothesized directional links. Standardized maximum likelihood parameters were used. ${ }^{*} p<.05 ; * * p<.01 ; * * *<.001$.

Significant actor effect $=$

Significant partner effect $=\longrightarrow$

Nonsignificant effect $=-\cdots---\rightarrow$ 
the comparative fit index (CFI), and (d) the nonnormed fit index (NNFI). A model in which the $\chi^{2} / d f$ was less than or equal to 2 , the CFI and NNFI were greater than 0.90, and the RMSEA index was between 0.00 and $0.09(\mathrm{Hu} \&$ Bentler, 1999) was deemed acceptable. These moderately stringent acceptance criteria clearly reject inadequate or poorly specified models but accept for consideration models that meet real-world criteria for reasonable fit and representation of the data (Kelloway, 1998).

\section{RESULTS}

Descriptive statistics for the humor styles, PTSD symptoms, depressive symptoms, and anxiety symptoms of the survivors and their spouses are presented in Table 1. Pairedsample $t$ tests indicated that the spouses reported using higher levels of affiliative and self-enhancing humor styles than the survivors. In addition, the survivors reported significantly higher levels of PTSD, depression, and anxiety symptoms than the spouses. The correlations between the humor styles and symptoms of the survivors and their spouses are presented in Table 2. Significant actor and partner effects were observed for the affiliative and selfenhancing styles of humor, which were found

TABLE 1. Differences Between the Humor Styles and Symptoms of Survivors and Their Spouses

\begin{tabular}{lrrrrrr}
\hline & \multicolumn{2}{c}{ Survivors } & & \multicolumn{2}{c}{ Spouses } \\
\cline { 2 - 3 } & \multicolumn{1}{c}{$M$} & $S D$ & & $M$ & $S D$ & $t_{[104]}$ \\
\hline Humor style & & & & & \\
Affiliative & 4.29 & 1.40 & & 4.63 & 0.98 & $-2.12^{*}$ \\
Self-enhancing & 3.32 & 1.55 & & 3.62 & 1.41 & $-1.96^{*}$ \\
Aggressive & 2.75 & 0.98 & & 2.75 & .94 & 0.06 \\
Self-defeating & 2.73 & 1.18 & & 2.62 & 1.02 & 0.76 \\
Symptoms & & & & & \\
PTSD & 54.32 & 17.14 & 39.92 & 15.22 & $9.51^{* *}$ \\
Depression & 13.23 & 7.31 & 8.50 & 6.29 & $7.77^{* * *}$ \\
Anxiety & 12.02 & 6.65 & 8.47 & 5.97 & $5.90^{* * *}$ \\
\hline
\end{tabular}

$* p<.05 ; * p<.001$. to be associated with all three manifest indicators of psychopathology symptoms (PTSD, depression, and anxiety). The only significant effect to emerge for the injurious humor styles concerned a negative association between the aggressive humor of the spouse and the depressive symptoms of the survivor. It is important to note that this was the only significant correlation to emerge for the injurious humor styles and trauma-related symptomatology out of 24 correlations. Accordingly, the APIM model included only the affiliative and self-enhancing humor styles.

The APIM model is presented in Figure 1. This model fit the observed data very well $\left(\chi^{2}[21]=27.88, p>0.15, \chi^{2} /\right.$ $d f=1.33$, NNFI $=0.97$, CFI $=.99$, RMSEA = 0.06). Controlling for the shared variance among the humor styles and symptoms of survivors and their spouses, we found that the affiliative humor of survivors was negatively associated with the survivors' symptoms $(\beta=-.33, t=-3.29, p=.001)$, but not with the symptoms of their spouses $(\beta=-.03, t=-0.19, p=.85)$. The selfenhancing humor of the survivors was found to be negatively associated with their symptoms $(\beta=-.42, t=-3.95, p<.001)$ and the symptoms of their spouses $(\beta=-.28, t=-2.02, p=.04)$. The affiliative humor of the unexposed spouses was found to be negatively associated with their symptoms $(\beta=-.33, t=-2.57, p=.01)$, as well as the symptoms of the survivors $(\beta=-.29$, $t=-2.04, p=.003)$. Finally, the self-enhancing humor of the unexposed spouses was not found to be significantly associated with their own symptoms $(\beta=.10, t=0.76$, $p=.45)$ or those of the survivors $(\beta=.14$, $t=1.35, p=.18)$. The model explained $53 \%$ of the variance in the symptoms of the survivors and $18 \%$ of the variance in the symptoms of the spouses. Taken together, these results suggest that the use of self-enhancing humor among survivors may help buffer their spouses from experiencing distress, whereas the use of affiliative humor among spouses may help to protect survivors from distress. 


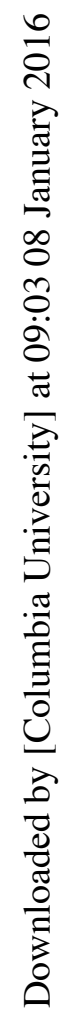

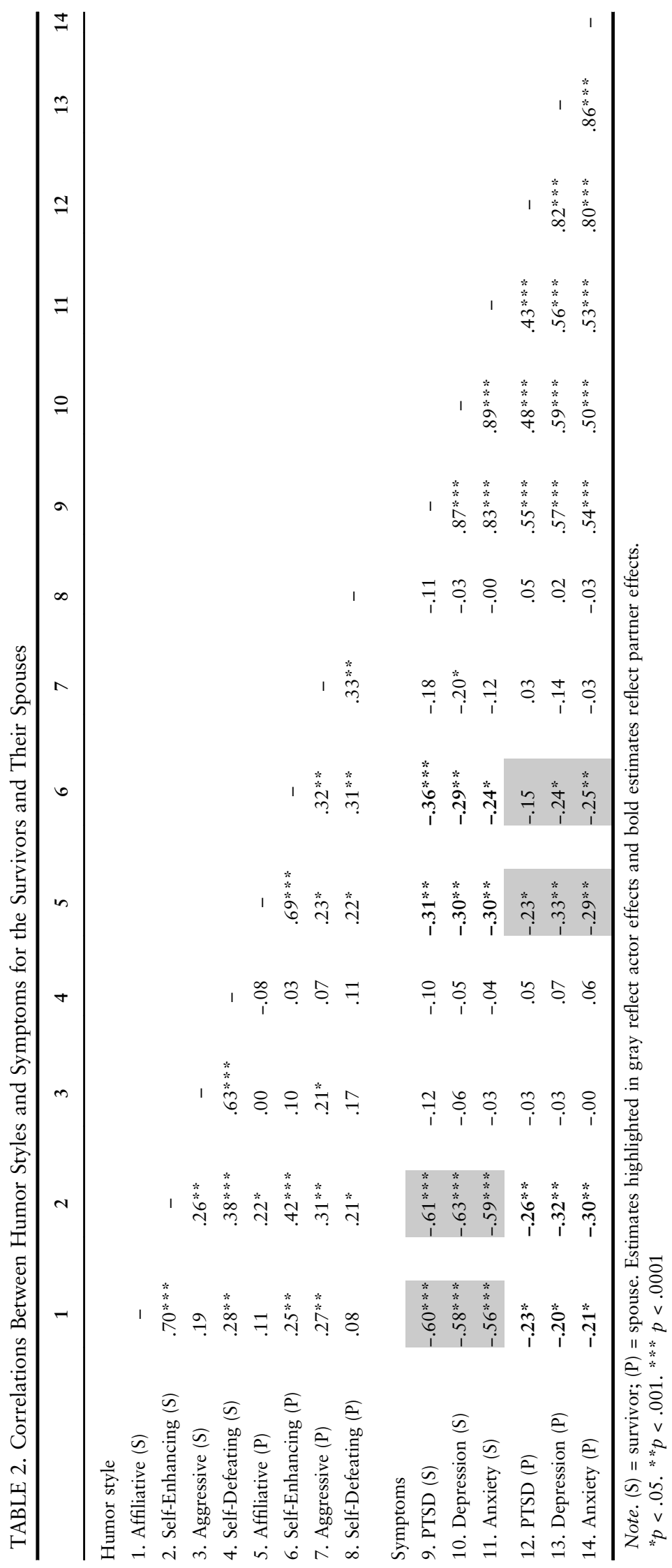




\section{DISCUSSION}

The primary aim of this study was to examine the bidirectional relationships that humor style had with PTSD, depression, and anxiety symptoms among survivors of terror attacks and their spouses. Consistent with our hypotheses, we observed positive associations between the symptoms (PTSD, depression, and anxiety) of survivors and their spouses. This provides additional support for the dyadic association between trauma survivors and their spouses (Gilbar et al., 2012; NelsonGoff \& Smith, 2005; Weinberg, 2011, 2013) and suggests this relationship is bidirectional. Thus, the unexposed spouse in the marital unit is not only affected by the traumatic experience of the survivor, but his or her own symptoms may influence the survivor. Although previous studies focused solely on PTSD symptoms in the context of the bidirectional survivor-spouse relationship, the present study demonstrates, for the first time, that the bidirectional nature of emotional distress within a couple may extend to depressive symptoms and anxiety symptoms. Thus, the study expands the theoretical framework and scope of the bidirectional relationship to include other consequences of trauma.

Consistent with previous studies (e.g., Besser et al., 2011; Besser et al., 2012; ZeiglerHill et al., 2013), we found the use of affiliative and self-enhancing humor styles to be associated with fewer symptoms for survivors of terrorist attacks. This provides additional support for the idea that humor-at least the benign forms of humor-may serve as an internal resource for trauma survivors that provides at least some protection from psychological distress. Moreover, the findings further suggest that the benign forms of humor may serve important interpersonal functions as indicated by the negative association that the self-enhancing humor of the survivors had with their symptoms as well as the symptoms reported by their spouses. The use of self-enhancing humor by survivors of terror attacks reflects the ability to maintain a humorous perspective in the face of adversity and so may convey resilience and positive emotion regulation. Survivors who use self-enhancing humor may tend to function more effectively and display a more positive perspective toward adversity and traumatic experiences, which may have an impact on the emotional states of their unexposed spouses (Figley, 1995). No significant association was found between the affiliative humor of the survivors and the symptoms of their spouses. One possible explanation for this pattern is that survivors may avoid or reduce their social interactions and activities following the traumatic experience. These changes may make it more difficult for the unexposed spouse to be affected by the affiliative humor of the survivor.

A link did emerge between the use of affiliative humor by the unexposed spouses and the symptoms reported by the survivors. One explanation for this pattern is that survivors may tend to focus on their difficulties following the terrorist attack and may find it difficult to maintain their connections with others. However, unexposed spouses who engage in affiliative humor may be better able to maintain their connections with the survivors by facing challenges to their relationships in a more positive and affirmative way. In accordance with the theoretical premise that the survivor-spouse relationship is bidirectional (Gilbar et al., 2012; Nelson-Goff \& Smith, 2005; Weinberg, 2013), the personal resilience of the unexposed spouse should have an impact on the marital unit resulting in less severe symptoms for both the spouse and the survivor.

The injurious styles of humor had almost no association with the symptoms reported by survivors and their spouses. The only exception was that the aggressive humor of the partner was negatively associated with the depressive symptoms reported by the survivor. These results are consistent with previous research (Agaibi \& 
Wilson, 2005; Henman, 2001) and provide additional support for the idea that injurious humor styles may not be particularly helpful for dealing with traumatic events. However, it is important to note that injurious humor styles were not associated with more symptoms. Rather, injurious humor styles simply had relatively little connection with traumarelated symptoms. These results suggest that it is important to distinguish between the benign and injurious styles of humor when considering the role of humor in psychological resilience as well indicating the need for further investigation into the connections that benign and injurious styles of humor may have with resilience following other events (e.g., divorce, unemployment, death of a child).

Considering that the average number of years since the terror attack in the present study was approximately 10 years, the findings further demonstrate the impact of the traumatic event on both the survivors and their spouses. It is reasonable to assume that over this period the pathological symptoms have been part of the daily lives of the survivors and their spouses. Nevertheless, although the distress symptoms are part of the negative effect of the traumatic experience, there is a significant association between humor styles and fewer pathological symptoms on both the personal level and the dyad level.

The results of the present study extend what is known about the dyadic relationship among survivors of terror attacks and their spouses and have both practical and clinical implications. These findings underscore the importance of the growing body of research regarding conjoint marital relationships for efforts to help the survivors of terrorist attacks and their spouses cope with traumatic experiences. Moreover, in devising a therapeutic framework, it is important to address, encourage, and reinforce the use of affiliative and self-enhancing humor styles. More specifically, in addressing the marital unit, the self-enhancing humor style of the survivor and the affiliative humor style of the spouse should be especially encouraged as they have dyadic associations with the distress reported by both the survivors and their spouses.

The present study had a number of strengths, including unique findings for a sample that includes both the survivors of terrorist attacks and their spouses. Nevertheless, several potential limitations should be noted. First, data concerning the emotional, functional, and psychosocial states of the participants prior to the terror attack were unavailable, which prevented us from examining whether any of these factors influenced the distress that resulted from the terror attack. Second, although the study utilized a substantial number of dyads drawn from the records of the OneFamily organization, the largest organization in Israel to provide support for survivors of terrorist attacks, it remains possible that our sample may not fully represent all of the individuals who may have experienced terror attacks, which may limit the generalizability of these findings. Third, the cross-sectional nature of the study does not allow us to establish causal relationships. Our underlying process model was that humor styles impact the symptoms that individuals experience in the wake of traumatic experiences, but we cannot rule out other explanations for the present results. For example, it is possible that psychological distress may impact the humor styles that individuals choose to utilize. Despite these limitations, we believe the present study makes a valuable contribution to our understanding of how individuals cope with potentially traumatic experiences-such as terrorist attacks-by shedding light on the importance of benign humor as resource for both survivors and their spouses.

\section{FUNDING}

The Study was supported by a Mission Awards grant from Psychology Beyond Borders 
(PBB). Grateful thanks are extended to the OneFamily organization and to all of the participants in this study. We wish to thank the anonymous reviewers for their very helpful comments on a draft of this article and the ideas involved.

\section{REFERENCES}

Agaibi, C. E., \& Wilson, J. P. (2005). Trauma, PTSD, and resilience: A review of the literature. Trauma, Violence, and Abuse, 6(3), 195-216. doi:10.1177/1524838005277438

American Psychiatric Association. (1994). Diagnostic and statistical manual of mental disorders (4th ed.). Washington, DC: American Psychiatric Association.

Arbuckle, J. L. (2009). AMOS: A structural equation modeling program. Chicago, IL: SmallWaters.

Besser, A., Luyten, P., \& Blatt, S. J. (2011). Do humor styles mediate or moderate the relationship between self-criticism and neediness, and depressive symptoms? Journal of Nervous and Mental Disease, 199, 757-764. doi:10.1097/ NMD.0b013e31822fc9a8

Besser, A., Luyten, P., \& Mayes, L. C. (2012). Adult attachment and distress: The mediating role of humor styles. Individual Differences Research, 10, 153-164.

Besser, A., \& Zeigler-Hill, V. (2011). Pathological forms of narcissism and perceived stress during the transition to the university: The mediating role of humor styles. International Journal of Stress Management, 18, 197-221. doi:10.1037/ a0024826

Brookmeyer, K., Henrich, C. C., Cohen, G., \& Shahar, G. (2011). Israeli adolescents exposed to community and terror violence: The protective role of social support. Journal of Early Adolescence, 31, 577-603. doi:10.1177/0272431610366247

Butzer, B., \& Kuiper, N. A. (2008). Humor use in romantic relationships: The effects of relationship satisfaction and pleasant versus conflict situations. Journal of Psychology, 142, 245-260. doi:10.3200/JRLP.142.3.245-260

Cann, A., Norman, M. A., Welbourne, J. L., \& Calhoun, L. G. (2008). Attachment styles, conflict styles, and humour styles: Inter-relationships and associations with relationship satisfaction.
European Journal of Personality, 22, 131-146. doi:10.1002/(ISSN)1099-0984

Catherall, D. R. (1992). Back from the brink: A family guide to overcoming traumatic stress. New York, NY: Bantam.

Dekel, R., Goldblatt, H., Keidar, M., Solomon, Z., \& Polliack, M. (2005). Being a wife of a veteran with posttraumatic stress disorder. Family Relations, 54, 24-36. doi:10.1111/fare.2005.54. issue-1

Ein-Dor, T., Doron, G., Solomon, Z., Mikulincer, M., \& Shaver, P. R. (2010). Together in pain: Attachment-related dyadic processes and posttraumatic stress disorder. Journal of Counseling Psychology, 57, 317-327. doi:10.1037/a0019500

Figley, C. (1995). Compassion fatigue as secondary traumatic stress disorder: An overview. In C. Figley (Ed.), Compassion fatigue: Coping with secondary traumatic stress disorder in those who treat the traumatized (pp. 1-20). New York, NY: Brunner/ Mazel.

Fitts, S. D., Sebby, R. A., \& Zlokovich, M. (2009). Humor styles as mediators of the shyness-loneliness relationship. North American Journal of Psychology, 11, 257-272.

Fonagy, P., Steele, M., Steele, H., Higgitt, A., \& Target, M. (1994). The Emmanuel Miller Memorial Lecture 1992: The theory and practice of resilience. Journal of Child Psychology and Psychiatry, 35, 231-257. doi:10.1111/ j.1469-7610.1994.tb01160.x

Galovski, T., \& Lyons, J. A. (2004). Psychological sequelae of combat violence: A review of the impact of PTSD on the veteran's family and possible intervention. Aggression and Violent Behavior, 9, 477-501. doi:10.1016/S1359-1789 (03)00045-4

Gervais, M., \& Wilson, D. S. (2005). The evolution and function of laughter and humor: A synthetic approach. Quarterly Review of Biology, 80, 395430. doi:10.1086/498281 
Gilbar, O., Weinberg, M., \& Gil, S. (2012). The effects of coping strategies on PTSD in victims of a terror attack and their spouses: Testing dyadic dynamics using an actor-partner interdependence model. Journal of Social and Personal Relationships, 29(2), 246-261. doi:10.1177/ 0265407511426939

Henman, L. (2001). Humor as a coping mechanism: Lessons from POWs. Humor, 8, 141-149.

Henrich, C. C., \& Shahar, G. (2008). Social support buffers the effect of terrorism on adolescent depression: Findings from Sderot, Israel. Journal of the American Academy of Child and Adolescent Psychiatry, 47, 1073-1076. doi:10.1097/CHI.0b013e31817eed08

Henry, S. B., Smith, D. B., Archuleta, K. L., SandersHahs, E., Nelson Goff, B. S., Reisbig, A. M., \& Scheer, T. (2011). Trauma and couples: Mechanisms in dyadic functioning. Journal of Marital and Family Therapy, 37(3), 319-332. doi:10.1111/ j.1752-0606.2010.00203.x

Hoyle, R. H., \& Smith, G. T. (1994). Formulating clinical research hypotheses as structural equation models: A conceptual overview. Journal of Consulting and Clinical Psychology, 62, 429-440. doi:10.1037/0022-006X.62.3.429

Hu, L., \& Bentler, P. M. (1999). Cutoff criteria for fit indexes in covariance structure analysis: Conventional criteria versus new alternatives. Structural Equation Modeling: A Multidisciplinary Journal, 6, 1-55. doi:10.1080/ 10705519909540118

Kelloway, E. K. (1998). Using LISREL for structural equation modeling: A researcher's guide. Newbury Park, CA: Sage.

Kenny, D. A., Kashy, D. A., \& Cook, W. L. (2006). Dyadic data analysis. New York, NY: Guilford Press.

Kroenke, K., Spitzer, R. L., \& Williams, J. B. (2001). The PHQ-9: Validity of a brief depression severity measure. Journal of General Internal Medicine, 16, 606-613. doi:10.1046/ j.1525-1497.2001.016009606.x

Kuiper, N. A., \& Leite, C. (2010). Personality impressions associated with four distinct humor styles. Scandinavian Journal of Psychology, 51, 115-122. doi:10.1111/(ISSN)1467-9450
Luyten, P., Fonagy, P., Lemma, A., \& Target, M. (2011). Mentalizing and depression. In A. Bateman \& P. Fonagy (Eds.), Handbook of mentalizing in mental health practice (pp. 385-417). Washington, DC: American Psychiatric Association.

Martin, R. A. (2001). Humor, laughter, and physical health: Methodological issues and research findings. Psychological Bulletin, 127, 504-519. doi:10.1037/0033-2909.127.4.504

Martin, R. A. (2007). The psychology of humor: An integrative approach. Burlington, MA: Elsevier.

Martin, R. A., Puhlik-Doris, P., Larsen, G., Gray, J., \& Weir, K. (2003). Individual differences in uses of humor and their relation to psychological well-being: Development of the humor styles questionnaire. Journal of Research in Personality, 37, 48-75. doi:10.1016/S0092-6566(02)00534-2

Miczo, N., Averbeck, J. M., \& Mariani, T. (2009). Affiliative and aggressive humor, attachment dimensions, and interaction goals. Communication Studies, 60, 443-459. doi:10.1080/ 10510970903260301

Nelson-Goff, B. S., \& Smith, D. B. (2005). Systemic trauma stress: The couple adaptation to traumatic stress model. Journal of Marital and Family Therapy, 31(2), 145-157. doi:10.1111/ j.1752-0606.2005.tb01552.x

Neria, Y., DiGrande, L., \& Adams, B. G. (2011). Posttraumatic stress disorder following the September 11, 2001, terrorist attacks: A review of the literature among highly exposed populations. American Psychologist, 66, 429446. doi:10.1037/a0024791

Neria, Y., Nandi, A., \& Galea, S. (2008). Posttraumatic stress disorder following disasters: A systematic review. Psychological Medicine, 38, 467-480. doi:10.1017/S0033291707001353

Shahar, G., Cohen, G., Grogen, K., Barile, J., \& Henrich, C. C. (2009). Terrorism-related perceived stress, adolescent depression, and friends' support. Pediatrics, 124, e235-e240. doi:10.1542/peds.2008-2971

Shalev, A. Y., \& Freedman, S. (2005). PTSD following terrorist attacks: A prospective evaluation. American Journal of Psychiatry, 162, 1188-1191. doi:10.1176/appi.ajp.162.6.1188 
Soffer-Dudek, N., Vertheim, R., \& Shahar, G. (2011). Lucid dreaming and resilience in the face of exposure to terrorism. Journal of Traumatic Stress, 24, 125-128. doi:10.1002/jts.20601

Spitzer, R. L., Kroenke, K., Williams, J. B., \& Lowe, B. A. (2006). Brief measure for assessing generalized anxiety disorder: The GAD-7. Archives of Internal Medicine, 166, 1092-1097. doi:10.1001/archinte.166.10.1092

Taber, K. H., Redden, M., \& Hurley, R. A. (2007). Functional anatomy of humor: Positive affect and chronic mental illness. Journal of Neuropsychiatry and Clinical Neurosciences, 19, 358-362. doi:10.1176/jnp.2007.19.4.358

Vaillant, G. E. (2000). Adaptive mental mechanisms: Their role in a positive psychology. American Psychologist, 55, 89-98. doi:10.1037/0003-066X.55.1.89

Weathers, F. W., \& Ford, J. (1996). Psychometric properties of the PTSD checklist (PCL-C, PCL-S, PCL-M, PCL-PR). In B. H. Stamm (Ed.), Measurement of stress, trauma, and adaptation (pp. 250252). Lutherville, MD: Sidran Press.

Weinberg, M. (2011). Spousal perception of primary terror victims' coping strategies and secondary trauma. Journal of Loss and Trauma, 16, 529-541. doi:10.1080/15325024.2011.576985

Weinberg, M. (2013). The bidirectional dyadic association between tendency to forgive, selfesteem, social support, and PTSD symptoms among terror-attack survivors and their spouses. Journal of Traumatic Stress, 26, 744-752. doi:10.1002/jts.2013.26.issue-6

Weinberg, M., Besser, A., Campeas, M., Shvil, E., \& Neria, Y. (2012). Civilians exposed to terrorism and war trauma in Israel: The role of intra- and inter-personal factors. In A. M. Columbus (Ed.), Advances in psychology research (Vol. 94, pp. 1-53). New York, NY: Nova Science Press.

Zeigler-Hill, V., \& Besser, A. (2011). Humor style mediates the association between pathological narcissism and self-esteem. Personality and Individual Differences, 50, 1196-1201. doi:10.1016/j. paid.2011.02.006

Zeigler-Hill, V., Besser, A., \& Jett, S. E. (2013). Laughing at the looking glass: Does humor style serve as an interpersonal signal? Evolutionary Psychology, 11, 201-226. doi:10.1177/ 147470491301100118 